\title{
Accelerated Creep Life Assessment of In-Service Power Plant Components
}

\author{
Saud Hamad Aldajah ${ }^{1, a}$, Mohammad Mazedul Kabir ${ }^{1}$ and Mohammad Y. Al-Haik \\ ${ }^{1}$ Electromechanical Engineering Program, Abu Dhabi Polytechnic, Abu Dhabi, UAE
}

\begin{abstract}
Structural metals used in plant components are subject to aging from a combination of fatigue, creep, and corrosion. Exposure to elevated temperatures promotes creep. Aged metals lose toughness, or the ability to absorb energy at stress above the yield point and cannot endure an occasional high load without fracturing. Creep is one of the most critical factors for determining the structural integrity of components. The main objective of the current study is to assess the remaining creep life of various 20-year old power plant engineering components such as the high temperature fasteners. Due to time constraints, the approach followed in this study was to utilize the accelerated high temperature creep testing in addition to Scanning Electron Microscopy (SEM) analysis to assess the remaining life of 4 different samples. The accelerated high temperature creep tests were conducted at a stress level of $61 \mathrm{MPa}$ and at a temperature of $1000^{\circ} \mathrm{C}$ for samples Sample 1 (original), Sample 2, Sample 3 and Sample 4; these samples were collected from different parts of the power plant. SEM analysis was carried out for all the samples. The results of the accelerated high temperature tests were compared to similar materials' theoretical creep data using Larson Miller curve. The Larson Miller actual creep lives of the tested samples were much higher than the experimental ones, which suggest that the samples are critically aged. SEM analysis on the other hand, showed that all samples have high percentage of creep voids.
\end{abstract}

\section{Introduction}

There is a considerable interest over the last few decades in extending the service life of major components in high-temperature plant applications beyond their original projected design life. Decisions on life extension have had to be made based on a number of key factors, including the metallurgical condition of the component, its previous service history, a reassessment of the original design calculations and the anticipated future service conditions to be experienced. Since life expectancy is, in reality, based on the ability of the material to retain its high-temperature creep strength for a period of at least twice the projected design life, methods of creep properties assessment based on physical changes in the material rather than simple parametric extrapolation are necessary.

There are many 30 to 40 -year-old thermal power plants that have exceeded their design lives. Structural metals used in plant components are subject to aging from a combination of fatigue, creep, and corrosion [1-3]. Exposure to elevated temperatures promotes creep. Aged metals lose toughness, or the ability to absorb energy at stress above the yield point and cannot endure an occasional high load without fracturing. Creep is one of the most critical factors for determining the structural integrity of components. To save energy and to meet recent regulatory requirements for $\mathrm{CO}_{2}$ emissions, as well as to improve thermal efficiency, steam pressures and operating temperatures in the components have been increased, resulting in accelerated material degradation. Furthermore, economic and environmental circumstances prohibiting the construction of new plants increase the severity of this problem. Non-destructive evaluation (NDE), for characterizing microstructures and damage initiation and growth, may become more widely used because of growing awareness of the benefit of using NDE techniques to assess the performance of components. In particular, NDE is becoming more significant for assessment of material degradation. An NDE technique that enables evaluation of the present state of materials and predicts their remaining life has long been sought [4-7].

Cr-MO-V (low alloy ferritic steel) type steel is used for high temperature application in power plants such as turbine rotor, boiler, steam pipes etc. This type of steel showed good service life at elevated temperature. The typical service temperature and stress of the low alloy ferritic steel in the power plant are about $550^{\circ} \mathrm{C}-600^{\circ} \mathrm{C}$ and $50-70 \mathrm{MPa}$ respectively. The high operating temperature of the steel material is the critical life limiting factor. High temperature operating condition lead to the degradation of the material's mechanical properties which results their short service life. To ensure the design life of the material with the safe operating service life a creep testing on the material need to

\footnotetext{
${ }^{\mathrm{a}}$ Corresponding author: saud.aldajah@adpoly.ac.ae
} 
perform to evaluate their mechanical property under high temperature condition. After prolonged service life of the material, the remaining life cycle assessment test can be performed by utilizing the creep testing at higher stress and temperature.

There are several candidates for creep-damage evaluation: magnetic techniques, surface replication (in situ optical metallography), small-angle neutron scattering (SANS), and ultrasonic techniques [3]. The magnetic techniques measure the change in the magnetic properties of a metal as they evolve due to creep progression [3-4], [6-7] and [8]. This method effectively senses the damage, but it is limited to ferromagnetic materials. The replication method can detect the microstructural state in highly localized surface regions [3], [9] and [10] and provides accurate information about microstructural changes. However, this method requires taking numerous microstructure samples from different locations and at different depths in order to obtain more reliable statistical information on the damage. In addition, it requires empirical judgment and careful analysis and is time-consuming and labour-intensive.

At high operating temperature, microstructural changes of the steel material occur. The changes in microstructure primarily composed of coarsening of carbides; compositional and morphological changes in the carbides, increase in the inter-particle spacing formation of new carbides, grain coarsening etc. The creep damage after prolonged service exposure in the form of grain boundary cavities has been rarely reported for Cr-Mo-V steel.

In this study, creep properties and microstructural analyses of the creep tested sample were studied. The detailed analyses of the morphological and compositional changes of the new and service exposed samples were conducted. Due to the availability of in-service used samples, the current project is adopting two techniques to examine the remaining creep life of the different inservice power plant engineering component. The first technique is the accelerated high temperature creep testing which tests various components at a stress level of $61 \mathrm{MPa}$ and a temperature of $1000^{\circ} \mathrm{C}$. The second technique is the SEM analysis of the microstructure of these components to reveal the formation of creep voids which can result in the formation of microcracks and eventually the fracture of the component.

\section{Experimental Details}

Creep properties of materials are those in which a material continues to elongate under constant load at the working temperature of a componen

Creep damage usually results in fracture, and creep properties of metallic materials are significant especially in, high-temperature steam lines, furnaces and burners. Creep testing reveals the life of a component under a certain stress and temperature. The creep test will result in a curve generally exhibiting three distinct phases. First-stage creep deformation is characterized by a rapid deformation rate that decreases slowly to a constant value. Second-stage creep deformation is characterized by a relative constant, low-deformation rate. The final or third-stage creep deformation is creep rupture, fracture, or breakage. The generalized uniaxial tensile creep behaviour of metals under constant load, isothermal temperature, and a given environment can be illustrated in Figure 1.

\subsection{Creep test:}

An accelerated high temperature creep testing were conducted under a constant temperature of $1000^{\circ} \mathrm{C}$ and a constant tensile stress of 61MPa for samples donated by Umm Al Nar Power Plant, Abu Dhabi, UAElabledas samples Original Sample 1 (S1), Sample 2 (S2), Sample 3 (S3) and Sample 4 (S4). The creep samples were cut using a water jet technique. The description of the samples is presented at Table 1. Stress-rupture testing machine as shown Figure 2 is used to evaluate the creep resistance of materials. In this test, the sample is subjected to a constant load and temperature, and the time to fracture is measured as it varies with stress and temperature. It is often used as an acceptance test for high-temperature materials since it can be performed more rapidly than creep testing can.

\subsection{SEM analysis:}

Scanning electron microscopy (SEM) was carried out for extensive morphological inspection of the fracture surfaces of the creep tested samples. The tested samples were dried under vacuum for $24 \mathrm{~h}$ at $50^{\circ} \mathrm{C}$. A total of 4 samples were prepared using fine polishing technique and itched with $2 \%$ nitol in order to be examined by the SEM. The coating of samples was carried out by gold sputtering and was further examined with an electron microscope (JEOL JSM-5600) for morphological analyses.

\section{Results and Analysis}

An accelerated high temperature creep testing was conducted for four samples. The sample location and material details are presented in Table 1. The test was carried out at $1000^{\circ} \mathrm{C}$ temperature with a tensile stress of $61 \mathrm{MPa}$. The results are shown in the Figure.

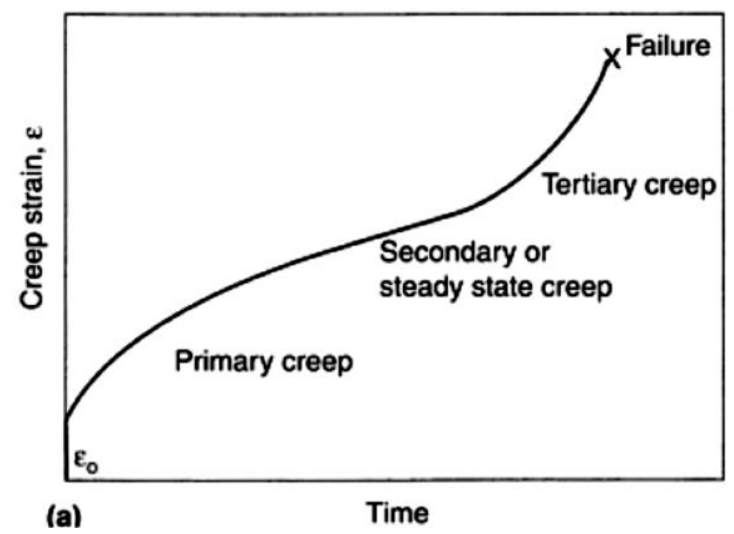

Figure. 1. A typical creep curve for metals 
Table 1. Sample description

\begin{tabular}{|l|c|c|c|c|c|}
\hline $\begin{array}{c}\text { Sample } \\
\text { code }\end{array}$ & Sample location & Material & $\begin{array}{c}\text { Operating } \\
\text { temperature }\end{array}$ & $\begin{array}{c}\text { Remaining Life based } \\
\text { on HT Creep Analysis* }\end{array}$ & $\begin{array}{c}\text { Rating based on void formation as compared } \\
\text { to original sample on a scale of 1-10 } * *\end{array}$ \\
\hline Sample 1 & Original sample & 24 CrMoV55 & $\begin{array}{c}\text { Stored at room } \\
\text { temperature }\end{array}$ & $100 \%$ & 10 \\
\hline Sample 2 & L.P Inner casing (turbine) & 24 CrMoV55 & $250^{\circ} \mathrm{C}$ & $73 \%$ & 5 \\
\hline Sample 3 & L.P control valve chamber & 24 CrMoV55 & $510^{\circ} \mathrm{C}$ & $55 \%$ & 6 \\
\hline Sample 4 & $\begin{array}{c}\text { Dist H.P steam main } \\
\text { isolating valve }\end{array}$ & $24 \mathrm{CrMoV55}$ & $490^{\circ} \mathrm{C}$ & $76 \%$ & 4 \\
\hline
\end{tabular}

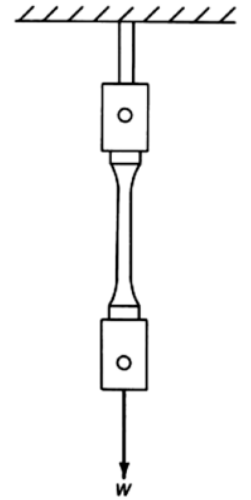

Figure. 2. Creep test setup

\subsection{Creep test analysis}

An accelerated high temperature creep testing was conducted for four samples. The goal of this is to measure the high temperature creep lives for in-service samples and compare them to the original one. The results are shown in the Figure 3. The original sample showed the best behaviour in terms of strain rate and rupture time.

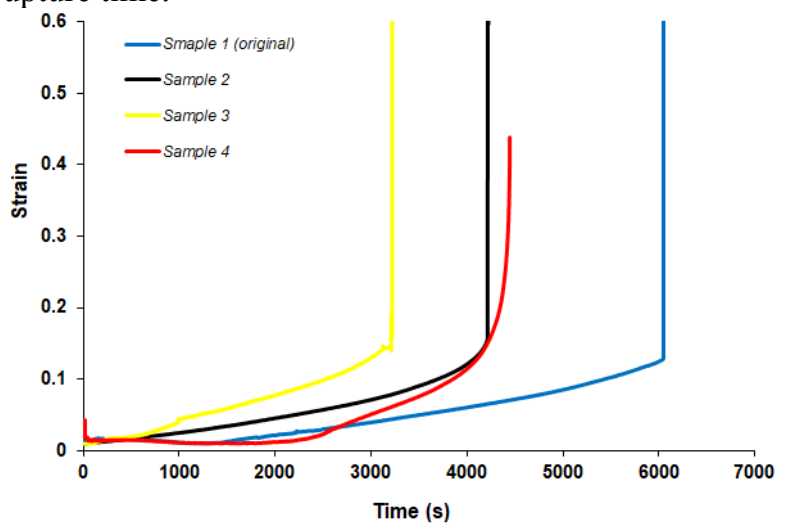

Figure. 3. High temperature Creep test

Larson Miller, Figure 4, which gives the rupture time at a given temperature and stress for steel curve was utilized. The experimental and theoretical data (from Larson Miller curve) were compared in Table 2. The results showed that all samples (S2, S3, and S4) showed that the creep life is dramatically less than the expected theoretical creep life obtained from Larson Miller curve.

Table2. Summary of the high temperature creep test results

Sample 3 showed the worst creep life with a rupture time of $0.92 \mathrm{hrs}$ compared to an expected life of $18.76 \mathrm{hrs}$. This means that the sample has a remaining life of $4.9 \%$ of the projected creep life. Similarly sample 2 and sample

4 have $6.2 \%$, and $6.6 \%$ of the projected creep life respectively. The ruptured samples are shown in figures 5.

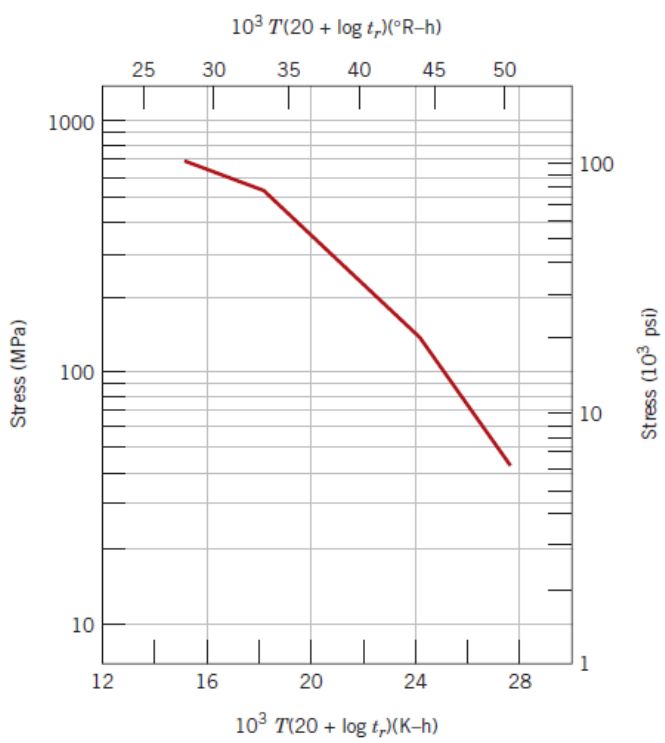

Figure 4. Larson Miller Curve

Table 2. Summary of the high temperature creep test

\begin{tabular}{|c|c|c|c|c|c|}
\hline No & $\begin{array}{c}\text { Experim } \\
\text { ental } \\
\text { Rupture } \\
\text { Time } \\
\text { (hr) }\end{array}$ & $\begin{array}{c}\text { Larson } \\
\text { Miller } \\
\text { Ruptur } \\
\text { e Time } \\
\text { (hr) }\end{array}$ & $\begin{array}{c}\text { strain } \\
\text { rate } \\
\mathbf{( 1 / h r )}\end{array}$ & $\begin{array}{c}\text { Exp. Strain } \\
\text { Rate (1/hr) }\end{array}$ & $\begin{array}{c}\text { Actual } \\
\text { Strain Rate } \\
\mathbf{( 1 / h r )}\end{array}$ \\
\hline S 1 & 1.68 & 18.76 & 0.05 & $2.1816 \mathrm{E}-09$ & $2.68739 \mathrm{E}-08$ \\
\hline S2 & 1.17 & 18.76 & 0.10 & $1.52244 \mathrm{E}-09$ & $2.43163 \mathrm{E}-08$ \\
\hline S3 & 0.92 & 18.76 & 0.14 & $1.1934 \mathrm{E}-09$ & $2.43163 \mathrm{E}-08$ \\
\hline S4 & 1.24 & 18.76 & 0.05 & $1.60128 \mathrm{E}-09$ & $2.43163 \mathrm{E}-08$ \\
\hline
\end{tabular}

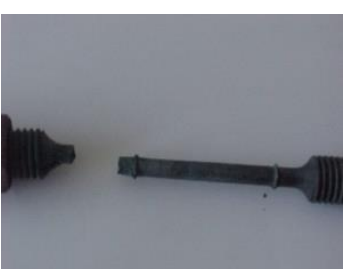

S1

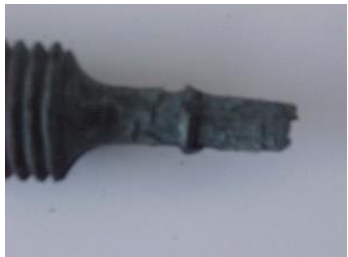

S3

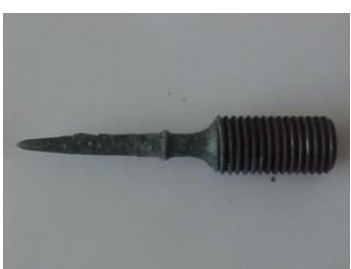

S2

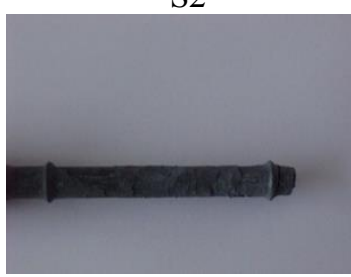

S4

Figure 5. Creep tested samples 


\subsection{Microstructure (SEM) Analysis}

Creep behaviour and degradation of creep properties of high-temperature materials are phenomena of major practical relevance, often limiting the lives of components and structures designed to operate for long periods under stress at elevated temperatures.

Because life expectancy is based on the ability of the material to retain its high-temperature creep strength for a period of at least twice the projected design life, methods of creep property assessment based on physical changes in the material that are likely to occur during service exposure. Therefore, SEM analysis is often adopted to examine the formation of creep voids in aged power plant engineering components. Creep voids usually promote the crack growth resulting in creep fracture.
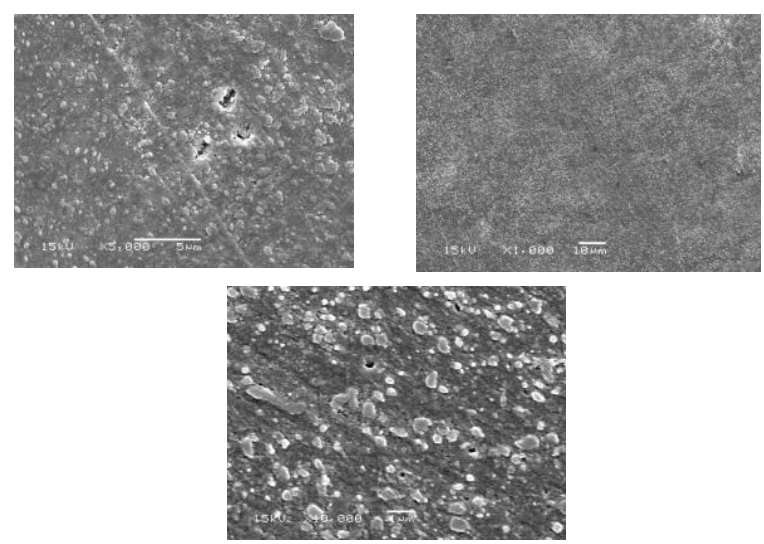

SEM images S1
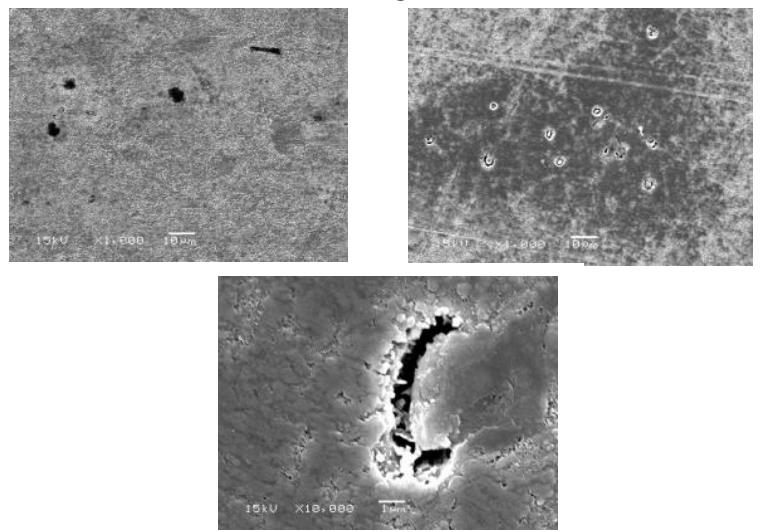

SEM images S2
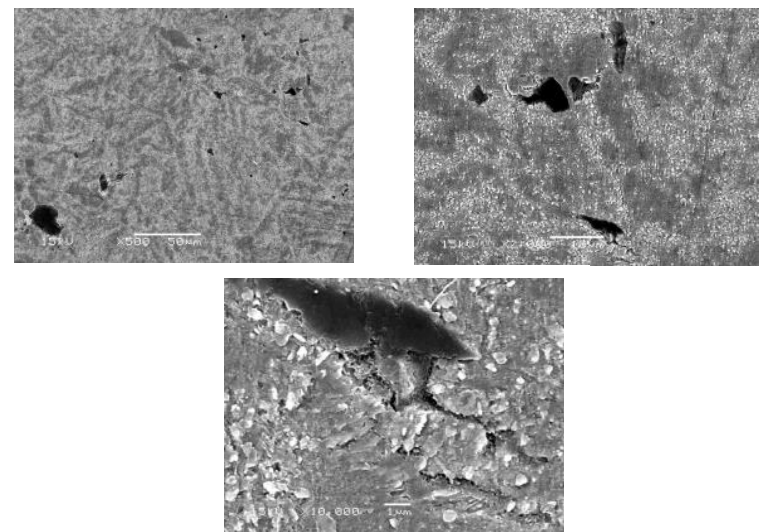

SEM images S3
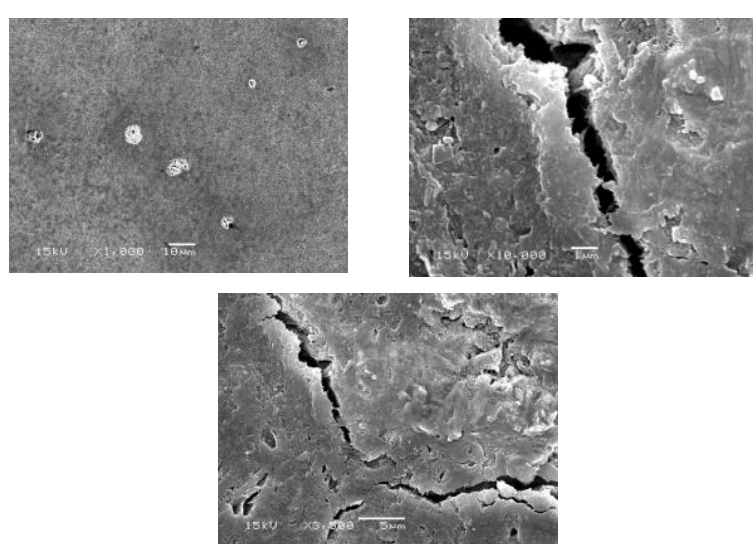

SEM images S4

Figure 6. SEM images of facture surfaces of the samples

A total of 15 samples were prepared using fine polishing technique and itched with $2 \%$ Nitol in order to be examined by the SEM. SEM images of all samples are shown in Figure 6. The figure shows that all sample have a high percentage of creep voids. In almost all samples these voids are developing into microcracks. These cracks are alarming since they may develop into large cracks and eventually result into a sudden fracture.

The above figures show that all samples, except the original sample, have a high percentage of creep voids. In almost all samples these voids are developing into microcracks. The original sample showed the formation of voids at the nano level whereas the other samples the voids are at the micro level. These cracks are alarming since they may develop into large cracks and eventually result into a sudden fracture.

\section{Conclusions}

High temperature accelerated tests were conducted for samples S2, S3 and S4. The results showed that these samples consumed most of their design life of approximately $94 \%, 95 \%$, and $93 \%$ respectively. If the initial design creep life at the power plant operation conditions of temperature and stress is 300,000 hrs, this means that the remaining creep life for these samples is $2.13,1.68,2.26$ and 3.07 years respectively.

SEM analysis showed that all samples, except the original, have a high percentage of creep voids. In almost all samples these voids are developing into microcracks. Original sample showed the formation of voids at the nano level whereas the other samples the voids are at the micro level. These cracks are alarming since they may develop into large cracks and eventually result into a sudden fracture.

The above mentioned analysis were compared to the available Larson Miller curve which gives the rupture time for the samples at a certain temperature and stress. A more accurate and conclusive result will be done if the creep tests were conducted at the same operating conditions of the power plant. This is a time consuming process which will take more than a year to be concluded. 
Due to the time limitations, the high temperature accelerated test was adopted.

\section{References}

1. Damage mechanism and life assessment of high temperature components. (1989). ASM International, Metals Park (OH). R. Viswanathan. p. 59.

2. R.B. Dooley, \& R. Viswanathan. (1987). Proceedings of the conference of ERPICS5208, Electric Power Research Institute, Palo Alto (CA).

3. B. Raj, V. Moorthy, T. Jayakumar, \& R.K. Bhanu Sankara. (2003). Int Mater Rev 48, p. 273.

4. G. Dobmann, M. Kroning, W. Theiner, H. Willems, \& U. Fiedler. (1995). Nucl Eng Design 157, p. 137.

5. P. Auerkari, \& J. Salonen. (1989). Int J Press Vessel Piping 39, p. 135.
6. R. Becker, G. Dobmann, M. Kronig, H. Reiter, \& E. Schneider. (1997). Int J Press Vessel Piping 73, p. 11.

7. D.S. Drion, P.K. Liaw, \& R.D. Rishel. (1992). Serviceability of petroleum process and power equipment. ASME PVP-vol.239/MPC-vol.33, p. 5.

8. A. Polar, J.E. Indacochea, M.L. Wang, V. Singh, \& G. Lloyd. (2004). Trans ASME J Eng Mater Technol 126, p. 393.

9. Advances in life prediction methods (1983). ASME, New York (NY), B.N eubauer, U. Wedel, D.A. Woodford, \& J.R. Whitehead. p. 307.

10. American Society for Testing and Materials, Philadelphia (PA) (1987). ASTM E12-87, D.M. Maric, P.F. Meier and S.K. Estreicher: Mater. Sci. Forum Vol. 83-87, Delong R.T. p. 119 